\title{
School Budgeting Planning: Selecting the Most Effective Budget Plan for Ontario's Public Schools
}

\author{
Hanin Alahmadi, Sirous Tabrizi \\ University of Windsor, Canada
}

\begin{abstract}
The main objective of this paper was to compare and contrast three school budgeting approaches namely, zero-based budgeting ( $Z B B)$, school-based budgeting $(S B B)$, and cycle-based budgeting $(C B B)$. $Z B B$ refers to a budget creation mechanism whose aim is to develop managerial control over agency funding requests. $Z B B$ comprises three strengths. First, it moves the firm away from the incremental budgeting. Second, it rationalizes cuts on the budget. Third, it is helpful in resource allocations within organizational departments. Nonetheless, ZBB has its weaknesses as it is managerial driven. Alternatively, under the SBB, the company's central office has the mandate to forecast the system vast revenue for a given fiscal year. A major strength of the approach is that people who best comprehend requirements play a pivotal in decision-making. However, the SBB can prove to be challenging to local managers in addition to encouraging conflict. CBB is understood as the combination of zero-based budgeting and grant application. Despite the challenges of CBB is being time-consuming and the fact that programs that are not aligned to the strategic priorities of the district may be affected. CBB is the best to utilize in Ontario schools because it employs decentralised funding and is fair.
\end{abstract}

\section{Introduction}

Funding for education in Ontario is done through the provincial funding formula, and it is based on the number of students in every school board. Most of the education funding is based on enrolment. Per-pupil funding is not purposed to be equal because different boards have unique needs. However, it is meant to provide equal opportunities for all students [1]. The province provides funding to the school board basing on various factors comprising of the number of schools, number of students in a board, and unique geographical needs of the board. Most funding can be transferred from one category to the other that means decisions on financings are made at the board level. School board make decisions on school budgets and establish criteria for things like the number of pupils a school needs to have to get librarians or principals. At the school level, principals made decision on internal expenses such as school maintenance, repair, and fundraised money.

Spending on public schools in 2015/16 amounted to $\$ 64.8$ billion, an increase of $\$ 16.0$ billion, or $32.6 \%$ since 2006 when spending on public schools was $\$ 48.9$ billion (see Table 1 and Figure 1). Spending in Ontario's schools increased over the last decade by $38.8 \%$.

\begin{tabular}{|c|c|c|c|c|c|c|c|c|c|c|c|}
\hline & 200622007 & $2007 / 2008$ & 20082009 & $2009 / 2010$ & 20102011 & 20112012 & 201222013 & 201322014 & 20142015 & $2015 / 2016$ & $\begin{array}{l}\text { \%o change, } \\
2006-07 \\
2015-16\end{array}$ \\
\hline Canada & 9,466 & 9,996 & 10,628 & 11,154 & 11,554 & 11,812 & 12,027 & 12,392 & 12,656 & 12,791 & $35.1 \%$ \\
\hline NL & 8,821 & 10,105 & 10,953 & 12,611 & 12,491 & 12,754 & 12,856 & 13,190 & 13,174 & 13,686 & $55.1 \%$ \\
\hline PE & 8,484 & 8,971 & 10,102 & 12,013 & 11,373 & 11,317 & 11,899 & 12,411 & 12,610 & 12,531 & $47.7 \%$ \\
\hline NS & 9,706 & 10,216 & 10,867 & 11,510 & 11,955 & 12,031 & 12,191 & 12,382 & 13,179 & 13,677 & $33.0 \%$ \\
\hline NB & 9,914 & 10,339 & 11,396 & 11,951 & 13,053 & 13,181 & 13,538 & 13,271 & 13,856 & 14,46 & $45.7 \%$ \\
\hline QC & 8,051 & 8,892 & 9,191 & 9,488 & 9,882 & 10,200 & 10,412 & 10,905 & 11,049 & 10,992 & $36.5 \%$ \\
\hline ON & 9,600 & 10,010 & 10,551 & 11,316 & 11,946 & 12,117 & 12,299 & 12,753 & 13,276 & 13,321 & $38.8 \%$ \\
\hline MB & 10,241 & 10,672 & 11,188 & 11,571 & 11,894 & 12,150 & 12,950 & 13,887 & 14,498 & 14,986 & $46.3 \%$ \\
\hline SK & 9,526 & 9,821 & 10,545 & 11,643 & 11,926 & 13,223 & 14,331 & 14,681 & 15,040 & 15,314 & $608 \%$ \\
\hline AB & 11,043 & 11,034 & 12367 & 13,235 & 13,537 & 13,564 & 13,302 & 13,460 & 13,197 & 13,430 & $21.6 \%$ \\
\hline$B C$ & 9,939 & 10,679 & 11,204 & 11,035 & 10,672 & 11,038 & 11,382 & 11388 & 11,216 & 11,656 & $20.2 \%$ \\
\hline
\end{tabular}

Table 1. Statistics of per student spending in Canada [18]

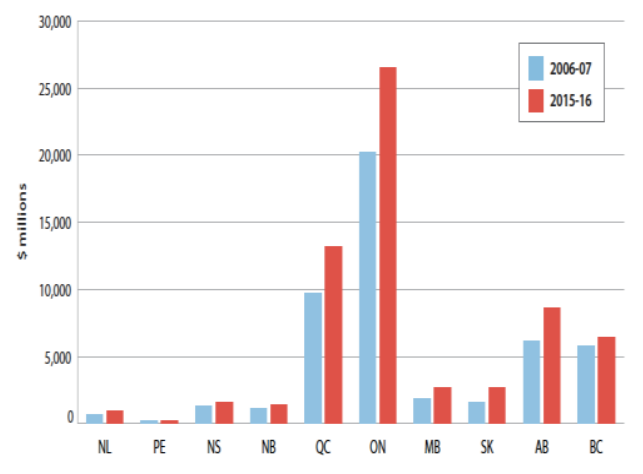

Figure 1. The amount of expenditure in millions (2006/07 to $2015 / 16)$ [18]

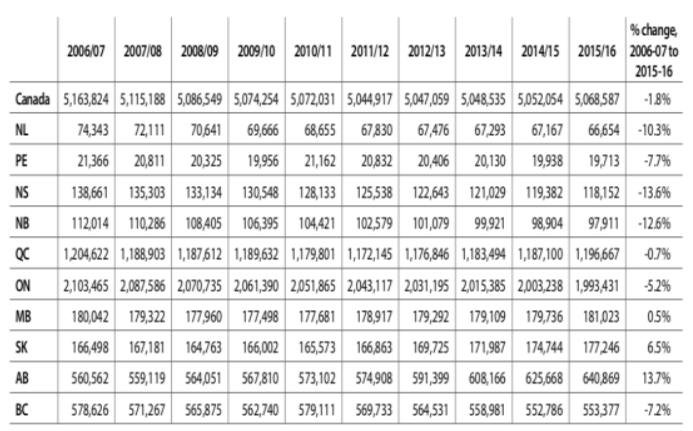

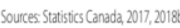

Table 2. Enrolment in public schools, 2006-07 to 2015-16 (number of students) [18] 


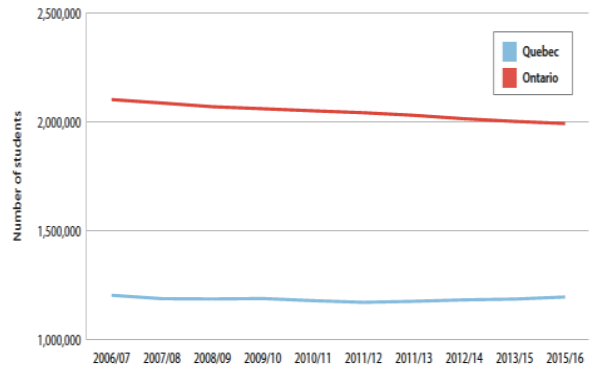

Figure 2. Students' enrolment in ON and QC (2006/07 to $2015 / 16)$ [18]

Table 2 contains enrolment data for Canada as a whole and for the individual provinces between 2006/07 and 2015/16, the most recent data available. Figures 2a illustrate the provincial enrolment over the same period for $\mathrm{ON}$, and QC. Total enrolment in public schools in Ontario had declined by $5.1 \%$ in 2006-2015 from 2.1 to 1.9 million students. This contradiction rises the alert for immediate reform in Ontario's schools budget planning.

Ontario budgeting planning is faced with various shortcomings since spending per pupil does not lead to improvement of the student's performance [2]. The second drawback is that the approach increases noncrucial spending. Spending of the funds is done on the non-important things leaving less money to books and payment of teacher's salaries. GSN regulations on funding are out-dated. One component of GSN is the Foundation Grants covers the necessary costs of educational experience, which is shared among all the students that are allocated based on the number of schools and school enrolment. The second component is Special Purpose grants address the unique needs of school boards and students related to board's demographic profile and location. An effective school budgeting establishes the opportunity for the leader to outline the priorities established in improvement plan [3]. Ontario had seen a spending rise by $4.1 \%$ in schools since 1996 [4].

The best way of allocation of funding and utilization of public resources effectively in the school system is an on-going process [5]. An effective approach requires gathering of information on increasing costs, evolving needs of students, and how well funding approaches support performance outcomes. Funding in Ontario has been widely felt and aid in the improvement of outcomes and attitudes amongst teachers and students [6]. Most of finances can be moved from one category to another, which means that many funding decisions are made at the board level. There are a few exceptions, where funding may not be moved. The province refers to it as "enveloped". Funding for special education, for student achievement in the Learning Opportunities Grant, and for capital expenditures is enveloped and cannot be spent for other purposes.

\section{Approaches to Budgeting Planning}

\subsection{Zero Based Budgeting}

Zero-based budgeting (ZBB) refers to a budget creation technique, which was established to advance the managerial control over the requests of agency funding. It also increases efficacy of the administration in distributing public funds to schools in Ontario. The original idea behind $\mathrm{ZBB}$ is that the organization needs to justify the whole budget every year. The primary purpose of the approach was to solve the predicament of assuming the previous year estimates at the initial point for the creation of the following year budget. Under ZBB, each agency is needed to identify the objectives which consist of ranking, reviewing and developing the decision packages, and identifying the corresponding units [7]. Thus, this technique includes specific procedures to be followed by every individual who is in charge of the agency unit. The person needs first to identify the unit objectives, actions required to attain them, the willpower of the various levels of the efforts plus the funding and effects of the functions of each unit. Afterward, via the rigorous procedure, the different levels of funding and efforts are analyzed and considered for every administrative rank via the application of specific criteria.

$\mathrm{ZBB}$ is an essential tool for guiding schools in Ontario to allocate its non-financial and financial resources better. Nevertheless, this approach requires every entity to re-evaluate yearly its activities. A methodological review of every function implies that managers ought to gather and analyze the massive data associated with every unit that is within the school. Budgeting for the complex organization is an insignificant case [7]. Nevertheless, this form of budget does not compromise dangerous and complicated assumptions of program dominations over the entities. It does not change the organizational structure. It might hence be more suitable for small and developing nations compared to large and complex countries with various programs.

$\mathrm{ZBB}$ has a variety of benefits and purposes if implemented well in schools in Ontario. When comparing it to the conventional line-time budgeting, it gives better information about the organizational activities. Additionally, compared to online budgeting, the zero-based budgeting process never attempts to change the structure of the program utilized by entities. It allows meaningful budget discussions, an improvement in the operational efficiency and effectiveness and improves discipline in budgets development [8]. Moreover, ZBB permits participation through low-level officials in the decision-making process of the budget. Furthermore, it allows all the concerned parties to review the goals and objectives of every unit in an organization. ZBB 
needs justification and scrutiny for the present programs, establishes budget yearly, and gives an excellent way of making judgments concerning the programs actual value.

ZBB starts from zero every year without any link to the past year's budget, and every addition to the budget requires a justification. The funding is created through the division of operations into the units of decisions [9]. Specific components are subsequently aggregated to the decision packages based on the goals of the program, events, and agency units. The main objective of $\mathrm{ZBB}$ is to re-examine all the programs for every budgeting cycle to justify its application when a new budget is created.

ZBB has three different strengths when implemented in Ontario, which make it useful. It moves the organizational away from the incremental budgeting; it rationalizes cuts on budget and is helpful in resource allocations within the departments. One of the weak points of the method includes being managerial driven. The second shortcoming of ZBB is that it fails to address service efficiency [9]. It is also assumed to require a lot of paperwork, and it is useful when appropriate performance measures are put in place. Advantages of zero-based operating budgeting include new programs that stand an equal chance of funding, management articulating initiatives, and encouraging a more significant understanding of the institution Disadvantages of ZBB entail being time-consuming, managers' spending time on reselling star programs, and lack of recognition of continuing commitments.

\subsection{School-Based Budget (SBB)}

Under school-based budgeting (SBB), central office is responsible for forecasting the vast system revenue for financial year. After the task is finalized, total revenue is divided amongst the amount retained to fund the centrally administered initiatives. Programs like bilingual education, special education, and transportation might be operated efficiently in the main office. Likewise, specialized services like legal department need to be based at central facility. Method of allocating non-central office part of entire revenue in overall considers various factors [10]. After the calculations of the school amounts, the agent at the school site decides on how the allocated funds are going to be spent.

School-based funding expresses actual authority for transaction of purchases plus short-term contracts. Instances of the probable expenditures' categories include maintenance, training, cleaning, personal, and curriculum materials. SBB can be enforced without varying structure of management at the school ground. When the principal has all the power to make all decisions, the mode of conducting operations is implemented under school-based budgeting [11]. Even though SBB puts extra burden of budget preparations, responsibilities would be typically included in principal's job description at charter or independent school. The trade-off is gaining control of decisions on expenditures plus savings in time of principle previously utilized in negotiating for resources with the main office in traditional budgeting structure.

Primary goal of school-based budgeting is maximization of money available for education. One method of accomplishing the goal is for increment of funds' allocations to the institutions in Ontario is through reduction of main office expenses plus the transfer of savings to facilities [10]. A different method of decreasing expenditures is through transferring decisions of spending to the agent of the school site who will be able to make better decisions on school expenditures. It is not realistic to expect the school-based budgets to produce improvement of outcomes of education. It appears that any successful implementation of SBB needs to include the successful implementation of the SBM. However, the SBB concentrations need to be confined to the areas it is meant for like school finance and be judged on the financial cost-benefit basis.

It is improper to demand SBB improve productivity on education in Ontario. Other commentators have indicated that the method's focus is not on saving of cost, but the increased production on education [11]. The term 'cost saving' is not clear and who is expected to benefit from it. It could be schools, central bureaucracy, or taxpayers. Rejection of first and second choices is understandable and almost certainly proposed by the commentators. One cannot presume that because resources have been utilized at the school level, it could be efficiently be allocated for the maximum impact on the learning of the students [12]. However, at minimum, every school if or not optimally allocated the resources could have more finances with necessary accountability that will develop a sufficient budget for the needs of the students.

SBB goals are mainly mentioned in the implementation publications of school systems, and the SBM literature is mostly used for justifying the process of SBB. For instance, the often-indicated goal is to improve school leadership [18]. SBB also enhances the purchased programs developed at school level ownership. There is the anticipation that the increased discretionary fund encourages educational innovations plus fundraising at the school ground. Apart from fundraising, other objectives are not economical; the anticipated outcomes are not quantifiable. These kinds of purposes include the goal to rise in production in education [12]. Provision of a fundraising incentive, the process of SBB needs to permit the schools to retain the surplus and not deduct the amounts of fundraising quantities from the funding allocation of school. Effectiveness of the latter might be dependent on every socioeconomic 
circumstance of school, a situation that might establish legal problems about district equity.

Following acceptance of SBB objective, there are connected policy issues to resolve in connection to school-based budget commitment in maximization of economic efficiency. The technical task is the determination of the amount of allocation for financing every school [13]. It necessitates the development of allocation formula for political reasons needs to be perceived as unbiased. The best method is allocation uniform per pupil. Nevertheless, adjustments need variables like grade levels, school size, and age of school, service length, and past inequities. Allocation formula is complicated when it is adapted to local conditions.

Policy decisions in Ontario schools need to be made in defining the scope of spending authority that is exercisable by school-site agent. When the facility is viewed as the decentralized loss and profit centre, as in the private sector, agents at school sites are responsible in the school operating result [13]. They need to be provided with maximum budget authority and responsibility in responding to the needs of the school and taking advantage of educational and local economic opportunities.

In school systems, the main limitation for spending power needs termination and hiring of the teachers whose employment terms are governed by the collective bargaining agreement [16]. School being a loss and profit model needs not to be accountable for the capital responsibilities plus other items like maintenance of reserves, utilities, hiring of substitute teachers, staffing, and professional development. Those responsibilities need to be controlled by the agent at the school site. Apart from spending authority, school-based budget implementation needs to address if a school will be allowed to carry forward savings to the following financial year. It ought to be done without offsetting budgetary allocation of subsequent year. Capacity to save could serve as school incentive in engaging local fundraising. Likewise, SBB needs to address how the operating loss of a school is dealt with appropriately. In England, the respective system gives the maximum autonomy to the schools that even have the authority in making capital expenditures. Institutions have the power of changing amounts at various budget categories without acquiring any permission.

School-based budget decentralizes the funding process and authority. Resources are distributed to individual sites with the budgetary allocation given to the school principal. The method permits alignment of objectives with resources [14]. It is deliberated as being practice for most schools. One of the strengths of school-based budgeting is that it includes those who best comprehend needs have the power in making decisions. Secondly, it gives greater accountability at the school level, and lastly, community plus staff are provided with the opportunity to have a voice. The weakness of SBB comprise of skills necessary for management process. Few officials at facility level undergo training to plan and oversee SBB. School-based budget can also amplify conflict.

\subsection{Cycle Based Budget (CBB)}

Cycle based budget is understood as the combination of zero-based budgeting and grant application. It was established to overcome the challenges of the $\mathrm{ZBB}$ and incremental budgeting model. On the use of the grant aspect, every new program needs to submit a budget request utilizing the online application form. During application, after filling out the budgets amounts and items, the request submitter requires to specify the measurable goals like raising the percentage of the students' meetings the standard of math by $3 \%$ or lowering discipline referrals by $4 \%$ plus the number of years to attain these goals [14]. CBB extends the review of the program plus the decision cycle of the budget. It is also more flexible compared to the other approaches.

The number of years is set on the application form; however, senior district leadership is responsible for final decisions that could either lengthen or shorten the cycle. The CBB expects the submitters in Ontario schools to be flexible and provide the number of years that is needed to attain the measurable objectives [15]. In the program cycle, performance and implementation data are reviewed plus monitored by the staff. It is done for adjustment purposes, but not by senior leadership of the district in making the decision. This aspect means that the program funding is secure except for when complications arise. At the end, if the program accomplishes the goals and continues to align with priorities of district, it will be evaluated with consequences of budget.

CBB model also improves the present accounting system by enabling the district to look at the budget from a different angle. Budget decisions and discussions on flexible spending mostly revolve on programs. After a plan is approved, nevertheless, the expenditure is frequently broken down into the items of budget and recorded utilizing the corresponding code of accounting [17]. Accounting system permit districts to track spending and provide an answer to questions like how much money is spent on services, salaries, supplies, and benefit of budget allocation. Nevertheless, if it fails in linking district's spending to concentrated areas and advancement plans, it is impossible to establish where the money is utilized appropriately.

Via the online application, CBB gives the missing link through allowing the district to track spending around the district strategic execution and planning. It also provides answers to questions like how much money was spent on discipline, math intervention, or literacy advancement. Most significantly, it permits 
the district to evaluate the return on the investment by looking at if the spending led to projected outcomes [19]. In overall, three main features of CBB assist in creation of space and time needed for the initiative to be planned thoroughly, closely monitored, implemented carefully, and reviewed. Comprehensible expectations are set at the beginning of the project, while accountability is demanded at the end [16]. Finally, limited monetary resources can be allocated depending on program's impact and implementation, hence making flexible spending.

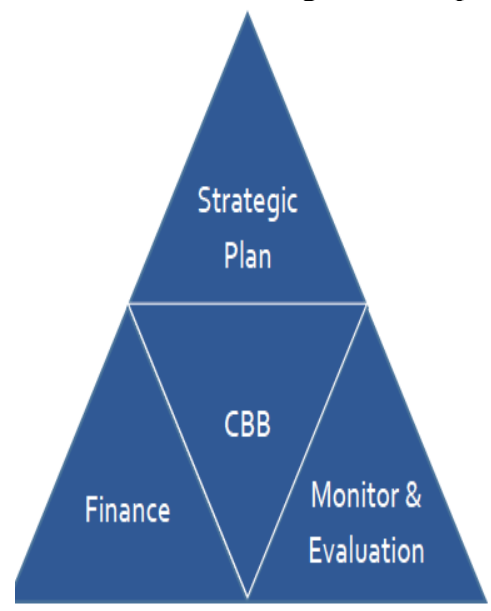

Figure 3. CBB Illustration

Challenges of cycle-based budgeting include being time-consuming, and programs which will are no longer aligned to the strategic priorities of the district will be affected. The conflicting role of administrators in making hard decisions concerning the process of the budget is another challenge to cycle based budgeting. However, overcoming these challenges could be achieved by measuring the students' academic outcomes of each program to determine its effectiveness and alignment with board's priorities. CBB also could benefit from employing National Center for Education Statistics (NCES) accounting model, which assists with tracking of spending of each program by addressing the deficiencies of the approach [20].

\section{Conclusion}

The paper focused on comparing and contrasting cycle-based (CBB), zero-based (ZBB), and schoolbased budgeting (SBB). Firstly, ZBB refers to a budget-creation mechanism, which advances managerial control over agency funding requests. ZBB consists of specific strengths, which include moving the company away from incremental budgeting, rationalizing cuts on budget, and assisting in resource allocation within departments. However, it is weak seeing that it is managerial-driven. Secondly, under the SBB, the organization's central office helps to forecast system's vast revenue for financial year. SBB also has strengths, and one of them is that it includes individuals who comprehend needs well and can contribute to decision-making. Nonetheless, local managers can struggle with SBB, and it can increase conflict. Thirdly, challenges of $\mathrm{CBB}$ are that it is time-consuming, and programs which are no longer aligned to strategic priorities of the district could be affected. However, CBB helps in decentralizing power. Research shows that decentralizing four key resources (power, information, knowledge, and rewards) can enhance organizational effectiveness and productivity [21]. In addition, fairness is another important issue. CBB deliberate this with more schools allocating resources according to their own core values [21]. Finally, among the three approaches, CBB is the best to utilize in Ontario schools because it applies decentralized funding and is fair.

\section{References}

[1] Cobb-Clark, D. A. and Jha, N. (2016) 'Educational Achievement and the Allocation of School Resources', Australian Economic Review, 49 (3), pp. 251-271.

[2] Garcea, J. and Munroe, D. (2014), 'Reforms to Funding Education in Four Canadian Provinces', Canadian Journal of Educational Administration and Policy, (159).

[3] GLISI (2007) 'Leading a Team to Design a School Budget', Georgia's Leadership Institute for School Improvement.

[4] Schmidt, S. (2005) Rising Per-Pupil Spending Soaking Up More Government Funds, CanWest News, Don Mills.

[5] GSN Guide (2018) '2018-19 Education Funding: A Guide to the Grants for Student Needs', GSN, http://www.edu.gov.on.ca/eng/funding/1819/guide-gsn2018-19-en.pdf (20 July 2019).

[6] GSN Summary (2018) '2018-19 Education Funding: Discussion Summary', GSN, http://www.edu.gov.on.ca/eng /funding/1819/gsn-discussion-summary-en.pdf (20 July 2019).

[7] McCauley, L. M. (2017) Budgeting for Small Schools, https://www.sacubo.org/-/media/sacubo/events/CBMI/ 2017/Handouts/BUD-2242-Budgeting-Small-Schools. ashx?la=en\&hash=5BCF297661EBC66B8F067F8C32B0E 61F8D2818CA (20 July 2019).

[8] Ahmad, A. A. A. (2007) 'Zero-Base Budgeting: Employees' Perceptions and Attitudes in Brunei Public Sector Organizations', Economics and Administration, 21 (1).

[9] Kavanagh, S. C. (2011) Zero-base Budgeting: Modern Experiences and Current Perspectives, Government Finance Officers Association, Chicago.

[10] Chan, L. (1997) 'School-based Budgeting: A CostBenefit Model', ERIC Digest, https://files.eric.ed.gov/ fulltext/ED422628.pdf (20 July 2019). 
[11] Dolloff, A. (2015) Resource Allocation in Maine's More Efficient Public High Schools, The University of Southern Maine, Portland.

[12] Pouncey, W. C., Ennis, L. S., Woolley, T. W. and Connell, P. H. (2013) 'School Funding Issues: State Legislators and School Superintendents - Adversaries or Allies?', Sage Open, 3 (2).

[13] Hanushek, E. A. and Dale W. J. (1996) Improving America's Schools: The Role of Incentives, National Academies Press, Washington.

[14] Zockoff, N. (2012). Smart school budgeting: Resources for districts. Rennie Center for Education Research \& Policy, 1-33.

[15] Miles, K. H., Ware, K. and Roza, M. (2003) 'Levelling the Playing Field: Creating Funding Equity through Student-Based Budgeting', Phi Delta Kappan, 85 (2), pp. 114-119.

[16] Yan, B. and Linick, M. (2016) 'Improving Efficiency in School Budgeting and Spending', Center for Education Policy Research, https://sdp.cepr.harvard.edu/files/ceprsdp/files/sdp-fellowship-capstone-efficiency-budgetingspending.pdf (20 July 2019).

[17] Yan, B. (2016) Cycle-based Budgeting Toolkit: A Primer,http://cyclebasedbudgeting.org/wp-content/ uploads/2016/09/CBB_A-primer.pdf (20 July 2019).

[18] Macleod, A. and Emes, J. (2019). Education Spending and Public School Enrolment in Canada, Fraser Institute, https://www.fraserinstitute.org/sites/default/files/education -spending-in-canada-2019_0.pdf (20 July 2019).

[19] National Research Council (1996) Improving America's Schools: The Role of Incentives, National Academies Press, Washington.

[20] Yan, B. (2018) 'Cycle-Based Budgeting', School Planning and Management, https://webspm.com/articles/ 2018/04/01/budgeting.aspx (20 July 2019).

[21] Wohlstetter, P., \& Van Kirk, A. (1995). School-Based Budgeting: Organizing for High Performance. Paper presented at the annual American Educational Research Association Conference, San Francisco. 